\title{
De novo assembly of the Carcinus maenas transcriptome and characterization of innate immune system pathways
}

Bas Verbruggen $^{1 *}$, Lisa K. Bickley ${ }^{1 \dagger}$, Eduarda M. Santos ${ }^{1}$, Charles R. Tyler ${ }^{1}$, Grant D. Stentiford ${ }^{2}$, Kelly S. Bateman ${ }^{2}$ and Ronny van Aerle $3^{3^{*}}$

\begin{abstract}
Background: The European shore crab, Carcinus maenas, is used widely in biomonitoring, ecotoxicology and for studies into host-pathogen interactions. It is also an important invasive species in numerous global locations. However, the genomic resources for this organism are still sparse, limiting research progress in these fields. To address this resource shortfall we produced a C. maenas transcriptome, enabled by the progress in next-generation sequencing technologies, and applied this to assemble information on the innate immune system in this species.

Results: We isolated and pooled RNA for twelve different tissues and organs from C. maenas individuals and sequenced the RNA using next generation sequencing on an Illumina HiSeq 2500 platform. After de novo assembly a transcriptome was generated encompassing 212,427 transcripts (153,699 loci). The transcripts were filtered, annotated and characterised using a variety of tools (including BLAST, MEGAN and RSEM) and databases (including NCBI, Gene Ontology and KEGG). There were differential patterns of expression for between 1,223 and 2,741 transcripts across tissues and organs with over-represented Gene Ontology terms relating to their specific function. Based on sequence homology to immune system components in other organisms, we show both the presence of transcripts for a series of known pathogen recognition receptors and response proteins that form part of the innate immune system, and transcripts representing the RNAi, Toll-like receptor signalling, IMD and JAKVSTAT pathways.

Conclusions: We have produced an assembled transcriptome for C. maenas that provides a significant molecular resource for wide ranging studies in this species. Analysis of the transcriptome has revealed the presence of a series of known targets and functional pathways that form part of their innate immune system and illustrate tissue specific differences in their expression patterns.
\end{abstract}

\section{Background}

In recent years, large scale sequencing studies have benefitted from the advance of high-throughput sequencing technologies that have resulted in substantial improvement in sequencing efficiency. Additionally, increases in the length and quality of sequencing reads have improved assemblies of sequenced genomes and transcriptomes. Sequencing is a powerful technique allowing for the rapid

\footnotetext{
*Correspondence: bv213@exeter.ac.uk; ronny.vanaerle@cefas.co.uk

${ }^{\dagger}$ Equal contributors

${ }^{1}$ Biosciences, College of Life \& Environmental Sciences, University of Exeter, Geoffrey Pope Building, Exeter EX4 4QD, UK

${ }^{3}$ Aquatic Health and Hygiene Division, Centre for Environment, Fisheries and Aquaculture Science (Cefas), Weymouth Laboratory, Weymouth, Dorset DT4 8UB, UK

Full list of author information is available at the end of the article
}

generation of transcriptome assemblies for any species of interest. Transcriptome sequencing measures expressed sequences only, thus does not have some of the challenges in DNA sequencing (e.g. long repeating sequences) [1]. De novo transcriptome assembly removes the need for a reference genome in quantitative RNA-Seq experiments, allowing for the rapid and accurate quantification of transcript abundance in a given biological sample. These aspects are especially useful in studies for organisms with limited genomic resources. Exemplary is the application of de novo transcriptome sequencing to a large range of organisms: vertebrates, e.g. brown trout (Salmo trutta) [2], invertebrates e.g. sea louse (Caligus rogercresseyi) [3], oriental fruit flies (Bactrocera dorsalis) [4] and the pollen beetles 
(Meligethes aeneus) [5], fungi (Trichoderma brevicompactum) [6] and other microorganisms.

Despite the rapid advances in sequence capabilities and in bioinformatics resources for generating high quality assemblies [7-9], de novo transcriptome studies in poorly characterized taxonomic groups continue to be challenging because of difficulties with annotation. This is due to the lack of information available on the genes of interest in closely related organisms. The subphylum Crustacea represents one such taxonomic group for which limited information exists. The Ensembl genome database for metazoan species contains mainly Diptera (flies), Nematoda (worms) and Hymenoptera (ants), but information on only a single crustacean: the common water flea, Daphnia Pulex [10]. Furthermore, the number of NCBI Entrez records in the invertebrate taxonomic branch shows huge under-representation of crustaceans. In total, there are approximately 2,300,000 nucleotide sequences in the subphylum Crustacea; in comparison the order Hymenoptera which alone contains almost 2,600,000 nucleotide sequences (numbers dated to April 2014). Consequently, subtaxa within the subphylum Crustacea contain less information: Decapoda (shrimps, crabs, lobsters and crayfish) have a total of 478,358 nucleotide and 44,210 protein sequences available.

The European shore crab (or green crab), C. maenas, is a keystone species in the European marine environment and is the only crustacean on the Global Invasive Species Database [11], with invasions into Australia, South Africa and the United States [12]. In such locations, C. maenas threatens local fishing industries, for example the destruction of the soft-shell clam (Mya arenaria) fishery in New England [13]. C. maenas is also an important study species for biomonitoring and ecotoxicology $[14,15]$. The species has been used in monitoring for heavy metal contamination [16], metal toxicity studies [17-22], and more recently in exposures studies with nanomaterials [23] and microplastics [24]. Pathological studies are a new area wherein $C$. maenas could play a role. A study investigating infection of crustaceans with White Spot Syndrome Virus (WSSV), recognized as the most significant pathogen affecting global shrimp aquaculture, showed that C. maenas are relatively resistant to the virus [25-27]. Despite its importance in these research areas, and its biological significance in the environment, the available molecular resources for $C$. maenas are extremely limited. To date, sequence data for this species comprises approximately 15,000 EST sequences and several hundred nucleotide and protein sequences [28].

Given the ecological importance of $C$. maenas, together with its wider general utility for research purposes, we aimed to sequence, assemble and annotate a shore crab transcriptome. We further set out to establish the relative expression profiles of all sequenced transcripts in different body tissues and organs, and to characterize immune pathways against those known for other invertebrates as a resource for future investigations on the response of this host to pathogens.

\section{Results and discussion}

\section{RNA sequencing and assembly}

Twelve sequence libraries corresponding to 12 pooled tissue samples from adult male and female C. maenas were sequenced on an Illumina HiSeq 2500 platform and yielded a total of $138,863,679$ paired reads across all tissues. After removal of low quality reads through quality filtering, there were 96,247,762 remaining paired reads. On average $8.0 \pm 1.7$ million read pairs were obtained for each tissue and the distribution of the reads per pooled transcript sample is presented in Table 1. The filtered RNA-Seq data were used for de novo transcriptome assembly using the Trinity pipeline with default parameters. The assembled transcriptome encompassed 196,966,469 bp distributed over 153,669 loci, represented by 212,427 transcripts (Table 2). The transcript lengths had a median of $380 \mathrm{bp}$ and a mean of $992 \mathrm{bp}$ (standard deviation $=1363 \mathrm{bp}$ ), and ranged between $201 \mathrm{bp}$ and 24,848 bp (Additional file 1 shows the length distribution of assembled transcripts). The transcriptome N50 was calculated to be 2,102 bp. $75.2 \%$ of the read pairs could be mapped back to the de novo assembled transcriptome using the bowtie 2 aligner.

A total of 231 out of the 248 highly conserved eukaryotic "core" genes were identified completely (93.15\%) and 245 genes $(98.79 \%)$ partially in the transcriptome by the CEGMA pipeline [29], indicating that the transcriptome contains a near complete set of core eukaryotic genes.

Table 1 Number of read pairs obtained for each crab tissue before and after removal of adapter sequences and quality filtering

\begin{tabular}{lll}
\hline Tissue sample & Number of read pairs & Number of clean read pairs \\
\hline Eggs & $9,337,648$ & $6,614,044$ \\
Epidermis & $11,929,821$ & $8,302,718$ \\
Eye & $13,463,765$ & $9,430,381$ \\
Gill & $10,110,102$ & $7,234,304$ \\
Haemolymph & $10,611,241$ & $7,233,253$ \\
Heart & $9,657,081$ & $6,717,788$ \\
Hepatopancreas & $9,216,408$ & $6,471,110$ \\
Intestine & $8,685,232$ & $5,765,077$ \\
Muscle & $17,251,355$ & $11,749,555$ \\
Nerve & $14,278,257$ & $9,670,912$ \\
Ovary & $11,125,170$ & $7,869,190$ \\
Testis & $13,197,599$ & $9,189,430$ \\
Total & $138,863,679$ & $96,247,762$ \\
\hline
\end{tabular}


Table 2 Transcriptome statistics

\begin{tabular}{ll}
\hline Description & Value \\
\hline Number of loci & 153,669 \\
Number of transcripts & 212,427 \\
Maximum transcript length (bp) & 24,848 \\
Minimal transcript length (bp) & 201 \\
Mean transcript length (bp) & 992 \\
Standard deviation (bp) & 1363 \\
Median transcript length (bp) & 380 \\
Total length (bp) & $196,966,469$ \\
N50 (bp) & 2,102 \\
\hline
\end{tabular}

\section{Transcriptome characterization}

Several approaches were taken to annotate the assembled transcripts. Firstly, the transcript sequences were compared to existing $C$. maenas EST sequences in the NCBI database using BLASTn. In total, 19,981 sequences (9.4\% of the total number of transcripts) showed high similarity to 4,759 EST sequences (30.6\% of total C. maenas ESTs in NCBI; Table 3). This indicates that the majority of transcripts in the assembly were previously un-reported for $C$. maenas. A broader sequence homology search was performed using BLASTx against the NCBI non-redundant $n r$ protein database and hits were found for 62,804 ( $29.6 \%)$ of the transcripts using an e-value threshold of 1e-3. Open reading frames were identified in $58,383(27.5 \%)$ of transcripts and the majority of the predicted peptides $(41,108)$, corresponding to $70.4 \%$ of all predicted peptides were annotated using the UniProt/Swissprot database (with an e-value cut-off of 1e-5). Furthermore, conserved Pfam domains were assigned to $37,776(67.4 \%)$ of the peptides and 4,132 (1.9\%) of these

Table 3 Number of annotated transcripts and open reading frames (identified by TransDecoder) using different annotation methods and sequence databases

\begin{tabular}{lll}
\hline Input & Annotation method & $\begin{array}{l}\text { Number of annotated } \\
\text { transcripts }\end{array}$ \\
\hline All transcripts & BLASTx - NCBI nr protein & $62,804(29.6 \%)$ \\
All transcripts & BLASTn - C.maenas EST & $19,891(9.4 \%)$ \\
All transcripts & BLAST2GO & $8,091(3.8 \%)$ \\
All transcripts & TransDecoder ORF finder & $58,383(27.5 \%)$ \\
All transcripts & KEGG & $30,352(14.3 \%)$ \\
$\begin{array}{l}\text { Open reading } \\
\text { frames }\end{array}$ & BLASTp - UniProt/ & $41,108(70.4 \%)$ \\
$\begin{array}{l}\text { Open reading } \\
\text { frames }\end{array}$ & SwissProt & $37,776(67.4 \%)$ \\
$\begin{array}{l}\text { Open reading } \\
\text { frames }\end{array}$ & SignalP & $4,132(1.9 \%)$ \\
$\begin{array}{l}\text { Open reading } \\
\text { frames }\end{array}$ & TmHMM & $0(0.0 \%)$ \\
\hline
\end{tabular}

peptides appeared to contain signal peptides (Table 3) as determined by SignalP. Transcriptome annotation details can be found in Additional files 2 and 3 .

\section{Transcriptome functional annotation}

Gene Ontology (GO) terms were assigned to 53,766 (25.3\%) of the annotated transcripts and $47.23 \%$ of the annotated predicted peptides (UniProt/Swissprot; Table 3) by BLAST2GO [30]. The most common GO terms were protein binding (10.93\%), cytoplasm (10.93\%), nucleus (10.07\%), plasma membrane (6.55\%) and membrane $(6.25 \%)$. The most common annotations for the three gene ontology trees are presented in Table 4, and a full list of transcript annotations is available in Additional file 4.

\section{Taxonomy}

The BLASTx output was used as input for MEGAN4 to illustrate the taxonomic origin of BLAST hits for the transcriptome in a phylogenetic tree. A partially collapsed phylogenetic tree is presented in Fig. 1. The taxon with the largest number of sequence homologies was the pancrustacean taxon wherein 21,642 C. maenas transcripts showed similarity. Within this taxon, transcripts were split between the crustacean and hexapoda taxa. Since C. maenas is a crustacean species it is expected that a large proportion of transcripts show similarity to sequences derived from this taxon. However, due to the limitations in crustacean genomic resources a significant proportion of transcripts mapped to related sequences in the hexapoda taxon instead (containing e.g. Drosophila melanogaster). Furthermore, it can be seen that a variety of sequences were derived from micro-organisms (e.g. bacteria, fungi and viruses), which may correspond to transcripts originating from micro-organisms living within the C. maenas hosts, and/or may reflect contamination of kits and samples with environmental micro-organisms [31]. To remove these potential contaminating transcripts from the transcriptome we filtered the transcriptome for sequences that mapped to the metazoan taxon. Following the application of this filtering step, a transcriptome encompassing 59,392 transcripts was retained and used in subsequent analysis.

\section{Differential gene expression}

Transcript expression in the twelve tissue types was estimated by the RSEM program [32]. Next, differentially expressed transcripts were identified through comparing gene expression profiles of each sampled tissue to the others. The number of differentially expressed (metazoan) transcripts for the various tissues ranged between 1,223 in gill and 2,741 in hepatopancreas (FDR $<0.01$; Table 5). All tissues showed enrichment for Gene Ontology (GO) terms; the top five for every tissue are listed in Table 6 (a complete list is presented in Additional file 5). 
Table 4 Identification, sequence similarity and Gene Ontology annotation statistics of peptide sequences in the transcriptome

\begin{tabular}{|c|c|c|c|}
\hline \multicolumn{2}{|l|}{ Description } & Number of sequences & Percentage of sequences (\%) \\
\hline \multicolumn{2}{|l|}{ Transcripts } & 212,427 & \\
\hline \multicolumn{2}{|l|}{ TransDecoder peptides } & 58,383 & \\
\hline \multicolumn{2}{|l|}{$\begin{array}{l}\text { Peptides with Swissprot } \\
\text { /Uniprot annotation }\end{array}$} & 41,108 & 70.41 \\
\hline \multicolumn{2}{|l|}{ GO annotated transcripts } & 53,766 & 25.31 \\
\hline \multicolumn{2}{|l|}{ GO annotated peptides } & 19,423 & 47.23 \\
\hline GO tree & GO & Count & $\%$ \\
\hline \multirow[t]{5}{*}{ Cellular Component } & cytoplasm & 2,122 & 10.9 \\
\hline & nucleus & 1,955 & 10.1 \\
\hline & plasma membrane & 1,272 & 6.6 \\
\hline & membrane & 1,213 & 6.3 \\
\hline & cytosol & 1,195 & 6.2 \\
\hline \multirow[t]{5}{*}{ Molecular Function } & protein binding & 2,577 & 13.3 \\
\hline & binding & 1,071 & 5.5 \\
\hline & ATP binding & 755 & 3.9 \\
\hline & metal ion binding & 569 & 2.9 \\
\hline & $\begin{array}{l}\text { protein homodimerization } \\
\text { activity }\end{array}$ & 485 & 2.5 \\
\hline \multirow[t]{5}{*}{ Biological Process } & cellular process & 597 & 3.1 \\
\hline & regulation of cellular process & 539 & 2.8 \\
\hline & primary metabolic process & 446 & 2.3 \\
\hline & response to stimulus & 419 & 2.2 \\
\hline & transport & 416 & 2.1 \\
\hline
\end{tabular}

The enriched GO terms often reflected the function of the tissue e.g. structural constituent of cuticle in eggs, angiogenesis in haemolymph and sarcolemma in muscle. In several tissues the link to function is not very clear in the top five, but becomes apparent in other enriched terms. For example, in the eye, phototransduction (FDR = $9.42 \mathrm{e}-4)$ and detection of light stimulus (FDR $=1.01 \mathrm{e}-3)$ were over-represented; contractile fibre $(\mathrm{FDR}=6.72 \mathrm{e}-3)$ and sarcomere $(\mathrm{FDR}=7.15 \mathrm{e}-3)$ were enriched in the heart tissue and finally, the epidermis and ovary tissues yielded only three enriched annotations (Table 6).

\section{Immune pathway characterization in C. maenas}

Application of $C$. maenas as a model organism to study crustacean infectious diseases requires insight in the organism's immune system. Since crustaceans do not have adaptive immune systems, innate immune strategies will predominate in this organism when responding to pathogenic insults. We investigated the presence of several innate immune system pathways in the $C$. maenas transcriptome and mapping the transcripts to pathways in the KEGG database. In total 30,352 (14.3\%) of transcripts were annotated to a KEGG orthology group (Table 3). The KEGG server [33] allows mapping of the present orthology groups to pathways in the KEGG database and visualization of presence/absence of their components. Li et al. 2013 characterized a selection of innate immune pathways in the hepatopancreas transcriptome of the mitten crab Eriocheir sinensis, including the RNAi pathway, Toll-like receptor pathway, immune deficiency (IMD) pathway, the JAK-STAT and mitogen activated protein kinase (MAPK) signalling pathways [34]. We characterized the same pathways in the $C$. maenas transcriptome with additions including the endocytosis pathway. The latter is not directly related to the immune response but many viruses utilize its machinery to gain entry to host cells [35]. Its characterization can thus be important for investigations of viral infections.

\section{Pathogen associated molecular pattern recognition}

The first stage in immune defence is the identification of invading pathogens by an organism. In this process a distinction between cells from the organism itself and those of the invading pathogens needs to occur. To achieve this, the innate immune system employs a group of pattern recognition receptors (PRRs) that are able to recognize pathogen associated molecular patterns (PAMPs). Examples of PAMPs include lipopolysaccharides, peptidoglycans and $\beta$-1,3-glucans [36] and groups of PRRs include gram-negative binding proteins 


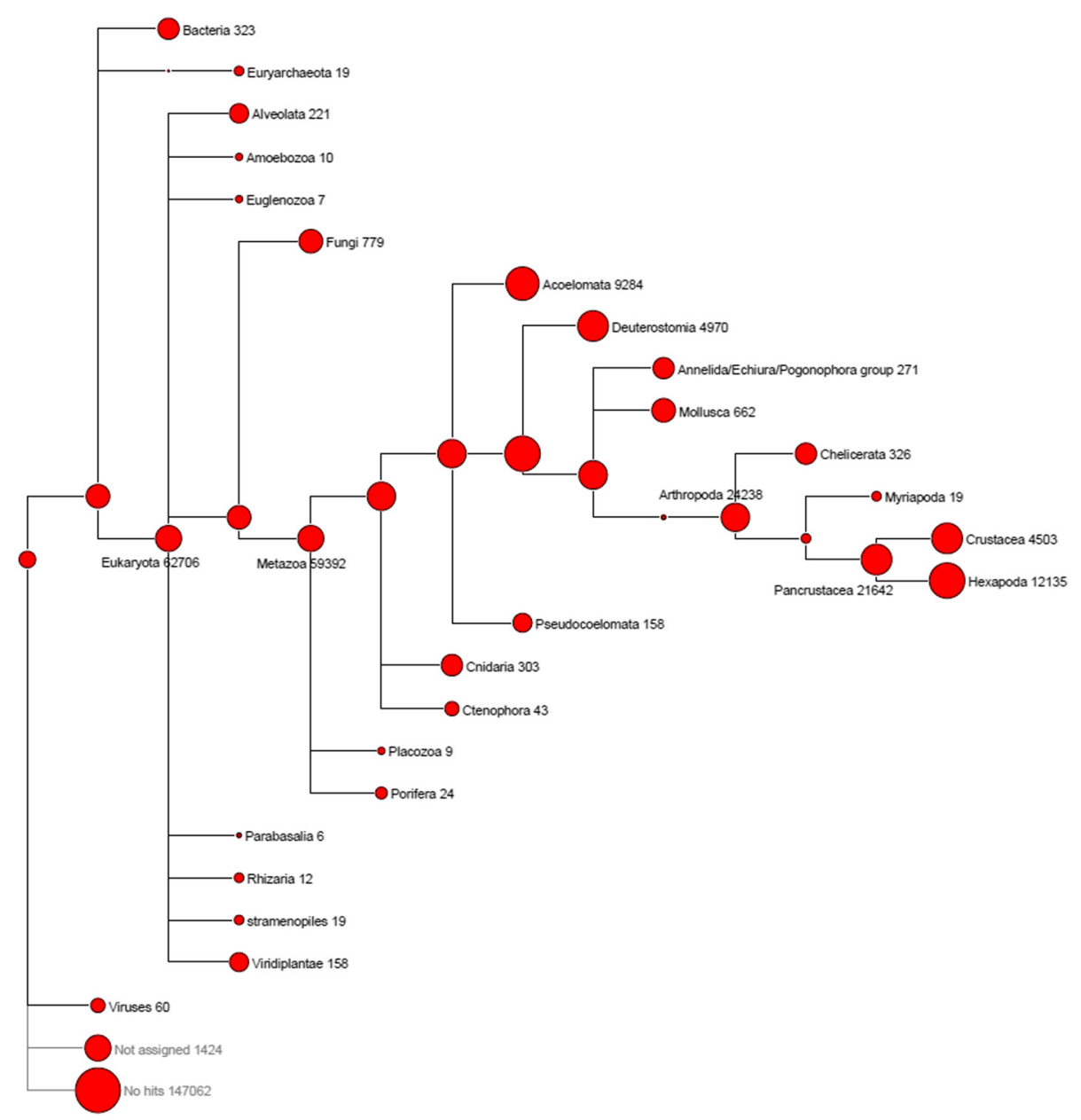

Fig. 1 Taxonomic classifications of Carcinus maenas transcripts. Partially collapsed phylogenetic tree produced by MEGAN4. Numbers illustrate the number of transcripts representing each taxa. Within the metazoan taxon, the pancrustacea represented the largest taxonomic group

Table 5 Differentially expressed transcripts in specific tissues

\begin{tabular}{ll}
\hline Tissue & Differentially expressed transcripts \\
\hline eggs & 1,605 \\
epidermis & 1,339 \\
eye & 1,312 \\
gill & 1,223 \\
Haemolymph & 2,008 \\
heart & 1,226 \\
hepatopancreas & 2,741 \\
intestine & 1,519 \\
muscle & 2,200 \\
nerve & 1,989 \\
ovary & 1,751 \\
testis & 1,391 \\
\hline
\end{tabular}

(GNBPs), peptidoglycan recognition proteins (PGRP), thioester containing proteins and lectins [36]. Upon successful pathogen recognition, PRRs initiate immune responses.

C. maenas transcripts that show sequence similarity to known PRR groups are shown in Table 7. Representatives of most groups of PRR have counterparts in the $C$. maenas transcriptome as identified through sequence similarity, often to sequences derived from organisms that are closely related to $C$. maenas. One group that is not represented are the PGRPs, this has also been reported in other crustacean species [37, 38]. Down syndrome cell adhesion molecule (Dscam) is a PAMP recognition protein that has been hypothesized to be involved in immune memory (reviewed in Armitage et al. 2014 [39]). This gene can produce many isoforms, and initial findings suggested that it played an important role in the development of the nervous system in invertebrates where Dscam isoforms aid in the discrimination 
Table 6 Top 5 most enriched Gene Ontology terms in specific tissues

\begin{tabular}{|c|c|c|c|c|}
\hline Tissue & GO-ID & Term & $P$ - value & FDR \\
\hline Eggs & GO:0042302 & structural constituent of cuticle & $9.86 \mathrm{e}-11$ & $1.07 e-6$ \\
\hline Eggs & GO:0003677 & DNA binding & $5.25 \mathrm{e}-7$ & $2.86 e-3$ \\
\hline Eggs & GO:0006260 & DNA replication & $2.78 \mathrm{e}-6$ & $1.01 \mathrm{e}-2$ \\
\hline Eggs & GO:0006261 & DNA-dependent DNA replication & $5.76 \mathrm{e}-6$ & $1.57 e-2$ \\
\hline Eggs & GO:0001708 & cell fate specification & $1.06 \mathrm{e}-5$ & $2.30 \mathrm{e}-2$ \\
\hline Epidermis & GO:0018298 & protein-chromophore linkage & $3.85 \mathrm{e}-7$ & $2.56 e-3$ \\
\hline Epidermis & GO:0015772 & oligosaccharide transport & $7.05 \mathrm{e}-7$ & $2.56 \mathrm{e}-3$ \\
\hline Epidermis & GO:0015766 & disaccharide transport & $7.05 \mathrm{e}-7$ & $2.56 e-3$ \\
\hline Eye & GO:0003008 & system process & $7.00 \mathrm{e}-12$ & $7.61 \mathrm{e}-8$ \\
\hline Eye & GO:0050877 & neurological system process & $2.36 \mathrm{e}-11$ & $1.28 \mathrm{e}-7$ \\
\hline Eye & GO:0022834 & ligand-gated channel activity & $9.64 \mathrm{e}-9$ & $2.62 e-5$ \\
\hline Eye & GO:0015276 & ligand-gated ion channel activity & $9.64 \mathrm{e}-9$ & $2.62 e-5$ \\
\hline Eye & GO:0070011 & $\begin{array}{l}\text { peptidase activity, acting on L-amino } \\
\text { acid peptides }\end{array}$ & $1.57 \mathrm{e}-8$ & $3.42 e-5$ \\
\hline Gill & GO:0070160 & occluding junction & $1.71 \mathrm{e}-6$ & $4.20 \mathrm{e}-3$ \\
\hline Gill & GO:0005344 & oxygen transporter activity & $1.84 \mathrm{e}-6$ & $4.20 \mathrm{e}-3$ \\
\hline Gill & GO:0015671 & oxygen transport & $1.84 \mathrm{e}-6$ & $4.20 \mathrm{e}-3$ \\
\hline Gill & GO:0015669 & gas transport & $1.84 \mathrm{e}-6$ & $4.20 e-3$ \\
\hline Gill & GO:0005923 & tight junction & $2.65 \mathrm{e}-6$ & $4.20 \mathrm{e}-3$ \\
\hline Haemolymph & GO:0001525 & angiogenesis & $5.76 \mathrm{e}-11$ & $6.27 e-7$ \\
\hline Haemolymph & GO:0048514 & blood vessel morphogenesis & $1.80 \mathrm{e}-9$ & $9.79 e-6$ \\
\hline Haemolymph & GO:0001568 & blood vessel development & $1.25 \mathrm{e}-8$ & $4.54 \mathrm{e}-5$ \\
\hline Haemolymph & GO:0001944 & vasculature development & $3.97 e-8$ & $1.08 \mathrm{e}-4$ \\
\hline Haemolymph & GO:0009653 & anatomical structure morphogenesis & $1.46 \mathrm{e}-7$ & $1.65 \mathrm{e}-4$ \\
\hline Heart & GO:0016328 & lateral plasma membrane & $1.78 \mathrm{e}-7$ & $1.94 \mathrm{e}-3$ \\
\hline Heart & GO:0006768 & biotin metabolic process & $1.28 \mathrm{e}-6$ & $3.04 \mathrm{e}-3$ \\
\hline Heart & GO:0004736 & pyruvate carboxylase activity & $1.28 \mathrm{e}-6$ & $3.04 \mathrm{e}-3$ \\
\hline Heart & GO:0005344 & oxygen transporter activity & $1.67 e-6$ & $3.04 \mathrm{e}-3$ \\
\hline Heart & GO:0015671 & oxygen transport & $1.67 \mathrm{e}-6$ & $3.04 \mathrm{e}-3$ \\
\hline Hepatopancreas & GO:0016491 & oxidoreductase activity & $6.35 e-16$ & $6.91 e-12$ \\
\hline Hepatopancreas & GO:0003824 & catalytic activity & $2.87 \mathrm{e}-11$ & $1.56 \mathrm{e}-7$ \\
\hline Hepatopancreas & GO:0044710 & single-organism metabolic process & $2.06 \mathrm{e}-10$ & 7.47e-7 \\
\hline Hepatopancreas & GO:0005576 & extracellular region & $5.68 \mathrm{e}-10$ & $1.20 \mathrm{e}-6$ \\
\hline Hepatopancreas & GO:0005764 & lysosome & $6.61 e-10$ & $1.20 \mathrm{e}-6$ \\
\hline Intestine & GO:0016337 & cell-cell adhesion & $5.72 \mathrm{e}-9$ & $6.22 \mathrm{e}-5$ \\
\hline Intestine & GO:0005548 & phospholipid transporter activity & $7.29 \mathrm{e}-8$ & 3.97e-4 \\
\hline Intestine & GO:0006022 & aminoglycan metabolic process & $1.56 \mathrm{e}-7$ & $4.06 \mathrm{e}-4$ \\
\hline Intestine & GO:0015917 & aminophospholipid transport & $2.09 \mathrm{e}-7$ & $4.06 \mathrm{e}-4$ \\
\hline Intestine & GO:0004012 & $\begin{array}{l}\text { phospholipid-translocating ATPase } \\
\text { activity }\end{array}$ & $2.09 \mathrm{e}-7$ & $4.06 \mathrm{e}-4$ \\
\hline Muscle & GO:0042383 & sarcolemma & $1.93 e-11$ & $2.10 \mathrm{e}-7$ \\
\hline Muscle & GO:0031674 & I band & $7.82 \mathrm{e}-11$ & $4.25 e-7$ \\
\hline Muscle & GO:0006811 & ion transport & $2.87 \mathrm{e}-10$ & $1.04 \mathrm{e}-6$ \\
\hline Muscle & GO:0030018 & $Z$ disc & $1.94 \mathrm{e}-9$ & $5.29 e-6$ \\
\hline Muscle & GO:0044449 & contractile fiber part & $2.54 \mathrm{e}-9$ & $5.52 \mathrm{e}-6$ \\
\hline
\end{tabular}


Table 6 Top 5 most enriched Gene Ontology terms in specific tissues (Continued)

\begin{tabular}{|c|c|c|c|c|}
\hline Nerve & GO:0015277 & $\begin{array}{l}\text { kainate selective glutamate receptor } \\
\text { activity }\end{array}$ & $1.39 \mathrm{e}-14$ & $1.51 \mathrm{e}-10$ \\
\hline Nerve & GO:0004872 & receptor activity & $2.54 \mathrm{e}-12$ & $1.38 \mathrm{e}-8$ \\
\hline Nerve & GO:0048172 & $\begin{array}{l}\text { regulation of short-term neuronal synaptic } \\
\text { plasticity }\end{array}$ & $5.16 \mathrm{e}-12$ & $1.87 \mathrm{e}-8$ \\
\hline Nerve & GO:0004970 & ionotropic glutamate receptor activity & $1.02 \mathrm{e}-11$ & $2.77 e-8$ \\
\hline Nerve & GO:0048168 & regulation of neuronal synaptic plasticity & $4.92 \mathrm{e}-11$ & $1.07 \mathrm{e}-7$ \\
\hline Ovary & GO:0016459 & myosin complex & $1.43 e-7$ & $1.56 \mathrm{e}-3$ \\
\hline Ovary & GO:0018298 & protein-chromophore linkage & $1.67 \mathrm{e}-6$ & $9.10 e-3$ \\
\hline Ovary & GO:0036002 & pre-mRNA binding & $1.37 e-5$ & $4.96 \mathrm{e}-2$ \\
\hline Testis & GO:0008499 & $\begin{array}{l}\text { UDP-galactose:beta- } N \text {-acetylglucosamine } \\
\text { beta-1,3-galactosyltransferase activity }\end{array}$ & $5.07 e-17$ & $5.52 \mathrm{e}-13$ \\
\hline Testis & GO:0035250 & UDP-galactosyltransferase activity & $1.45 e-16$ & $7.86 \mathrm{e}-13$ \\
\hline Testis & GO:0005797 & Golgi medial cisterna & $1.38 \mathrm{e}-15$ & $5.00 \mathrm{e}-12$ \\
\hline Testis & GO:0048531 & beta-1,3-galactosyltransferase activity & $6.12 \mathrm{e}-15$ & $1.66 \mathrm{e}-11$ \\
\hline Testis & GO:0008378 & galactosyltransferase activity & $1.26 \mathrm{e}-14$ & $2.75 e-11$ \\
\hline
\end{tabular}

Table 7 Carcinus maenas pathogen associated molecular pattern recognition genes

\begin{tabular}{|c|c|c|c|c|c|c|}
\hline PRP group & Transcript & Identity (\%) & Length & E-value & Query & Ancestor \\
\hline \multirow[t]{7}{*}{ GNBP } & comp44152_c0_seq1 & 42.06 & 340 & $1.00 \mathrm{e}-65$ & $\begin{array}{l}\text { gi|300507044 : gram-negative binding } \\
\text { protein [Artemia sinica] }\end{array}$ & Crustacea \\
\hline & comp44453_c0_seq (1-2) & 58.06 & 341 & $3.00 e-123$ & gi|62122584 : GNBP [Oryzias latipes] & Bilateria \\
\hline & comp74133_c0_seq1 & 44.8 & 346 & $8.00 \mathrm{e}-88$ & gi|62122584 : GNBP [Oryzias latipes] & Bilateria \\
\hline & comp83740_c0_seq (1-5) & 46.02 & 339 & $5.00 \mathrm{e}-87$ & gi|62122584 : GNBP [Oryzias latipes] & Bilateria \\
\hline & comp19734_c0_seq1 & 41.55 & 142 & $8.00 e-32$ & gi|62122584 : GNBP [Oryzias latipes] & Bilateria \\
\hline & comp136078_c0_seq1 & 62.96 & 81 & $3.00 \mathrm{e}-26$ & gi|62122584 : GNBP [Oryzias latipes] & Bilateria \\
\hline & comp75261_c0_seq1 & 27.57 & 243 & $6.00 \mathrm{e}-22$ & gi|62122584 : GNBP [Oryzias latipes] & Bilateria \\
\hline \multirow[t]{8}{*}{ TECP } & comp85313_c2_seq1 & 39.94 & 318 & $6.00 e-63$ & $\begin{array}{l}\text { gi|385049105: thioester containing } \\
\text { protein 3, partial [Daphnia parvula] }\end{array}$ & Crustacea \\
\hline & comp65627_c0_seq1 & 46.34 & 246 & $3.00 \mathrm{e}-58$ & $\begin{array}{l}\text { gi|54644242 : Thioester-containing } \\
\text { protein } 6 \text { [Drosophila pseudoobscura pseudoobscura] }\end{array}$ & Pancrustacea \\
\hline & comp87629_c0_seq4 & 74.36 & 234 & $6.00 e-101$ & gi|331031264 : TEP isoform 2 [Pacifastacus leniusculus] & Pleocyemata \\
\hline & comp74624_c1_seq1 & 40.65 & 310 & $8.00 \mathrm{e}-56$ & $\begin{array}{l}\text { gi|385049099 : thioester containing } \\
\text { protein 3, partial [Daphnia pulex] }\end{array}$ & Crustacea \\
\hline & comp65627_c1_seq1 & 36.78 & 590 & $6.00 \mathrm{e}-118$ & $\begin{array}{l}\text { gi|54644242 : Thioester-containing } \\
\text { protein } 6 \text { [Drosophila pseudoobscura pseudoobscura] }\end{array}$ & Pancrustacea \\
\hline & comp74624_c2_seq1 & 37.83 & 534 & $1.00 \mathrm{e}-105$ & $\begin{array}{l}\text { gi|54644242: Thioester-containing protein } \\
6 \text { [Drosophila pseudoobscura pseudoobscura] }\end{array}$ & Pancrustacea \\
\hline & comp85313_c0_seq1 & 38.14 & 430 & $1.00 \mathrm{e}-80$ & $\begin{array}{l}\text { gi| } 568250870 \text { : thioester-containing } \\
\text { protein [Anopheles darlingi] }\end{array}$ & Pancrustacea \\
\hline & comp103781_c0_seq1 & 43.36 & 113 & $4.00 \mathrm{e}-22$ & $\begin{array}{l}\text { gi|54644242 : Thioester-containing } \\
\text { protein } 6 \text { [Drosophila pseudoobscura pseudoobscura] }\end{array}$ & Pancrustacea \\
\hline \multirow[t]{6}{*}{ C-Type Lectin } & comp69837_c0_seq1 & 43.15 & 146 & $1.00 \mathrm{e}-25$ & gi|558633447 : C-type lectin [Marsupenaeus japonicus] & Decapoda \\
\hline & comp86095_c0_seq (1-2) & 43.92 & 148 & $2.00 e-25$ & gi|558633447 : C-type lectin [Marsupenaeus japonicus] & Decapoda \\
\hline & comp68699_c0_seq1 & 38.89 & 144 & $1.00 \mathrm{e}-24$ & gi|558633447 : C-type lectin [Marsupenaeus japonicus] & Decapoda \\
\hline & comp87731_c3_seq (2-3) & 33.78 & 225 & $8.00 e-25$ & $\begin{array}{l}\text { gi|657397985 : C-type lectin receptor-like } \\
\text { tyrosine-kinase plant [Medicago truncatula] }\end{array}$ & Eukaryota \\
\hline & comp88573_c0_seq (1-2) & 57.5 & 80 & $4.00 \mathrm{e}-22$ & $\begin{array}{l}\text { gi|676264911 : C-type lectin domain family } \\
3 \text { member A [Fukomys damarensis] }\end{array}$ & Bilateria \\
\hline & comp90611_c0_seq1 & 64.56 & 158 & $5.00 e-60$ & gi|575878533 : C-type lectin [Scylla paramamosain] & Portunoidea \\
\hline
\end{tabular}


of neuritis [39]. Dscam isoforms were later found to be able to recognise pathogens, aiding in phagocytosis [40]. In concordance with this hypothesis, the C. maenas Dscam gene appears to encode many isoforms, and in total 242 transcripts with significant similarity to Dscam sequences in NCBI were found in the transcriptome.

The immune responses initiated by these PRRs can occur at a transcriptional level, e.g. activation of Toll and IMD can aid in phagocytosis e.g. Dscam binding, or can initiate proteolytic cascades leading to melanization.

\section{Toll-like receptor pathway}

The Toll receptor pathway is a signalling route that responds to the presence of PAMPs by ultimately activating Nf- $k B$ [41]. In mammals, Toll-like receptors (TLR) bind to PAMPs resulting in dimerization. Upon forming dimers, the TLRs recruit MyD88 and subsequently IRAK kinases. After IRAK kinases activate TRAF6, its binding to TAK1 and IKK $\beta$ ultimately frees Nf- $\mathrm{KB}$ to diffuse into the nucleus [42]. In invertebrates, such as $D$. melanogaster, the mechanism is slightly different, and instead of directly binding PAMPs, TLRs respond to the Toll ligand Spätzle [41].

The KEGG database contains a version of the Toll-like receptor pathway which was used to visualize the coverage of this pathway in the C. maenas transcriptome (see Fig. 2). Homologues were found for most of the components in the paths from TLR to NF- $\mathrm{kB}$ and activator protein-1 (AP-1). Since KEGG is targeted towards vertebrate genes and pathways, a characterization of an invertebrate Toll signalling pathway was also performed (see Methods for pathway analysis strategy). Components of the $D$. melanogaster Toll signalling pathway were taken from Li et al. [34] and Kingsolver et al. [41] and investigated for presence and expression in the assembled transcriptome. Transcripts with significant sequence similarity to most of the Toll pathway components were found in the transcriptome (Additional file 6). Tube, an IRAK homolog, was not identified in the C. maenas transcriptome. Successfully identified transcripts were found to be expressed across all tissues (Additional file 7), and the median expression values varied from 82.4 FPKM for myD88 to 5576.7 FPKM for Toll.

\section{IMD pathway}

The IMD pathway is also activated upon pathogen recognition, in particular by Gram-negative bacteria. Similar to Toll-like receptors, the binding of peptidoglycan by PGRPs leads to dimerization [41]. After the dimerization, the signal is transmitted through IMD, as well as FADD and DREDD. Activation of DREDD leads to poly-ubiquitination of IMD [41], binding of TAK1 and assembly of the IKK complex. Relish phosphorylation is promoted by IKK, and an event followed by cleavage of Relish by DREDD cause translocation of the

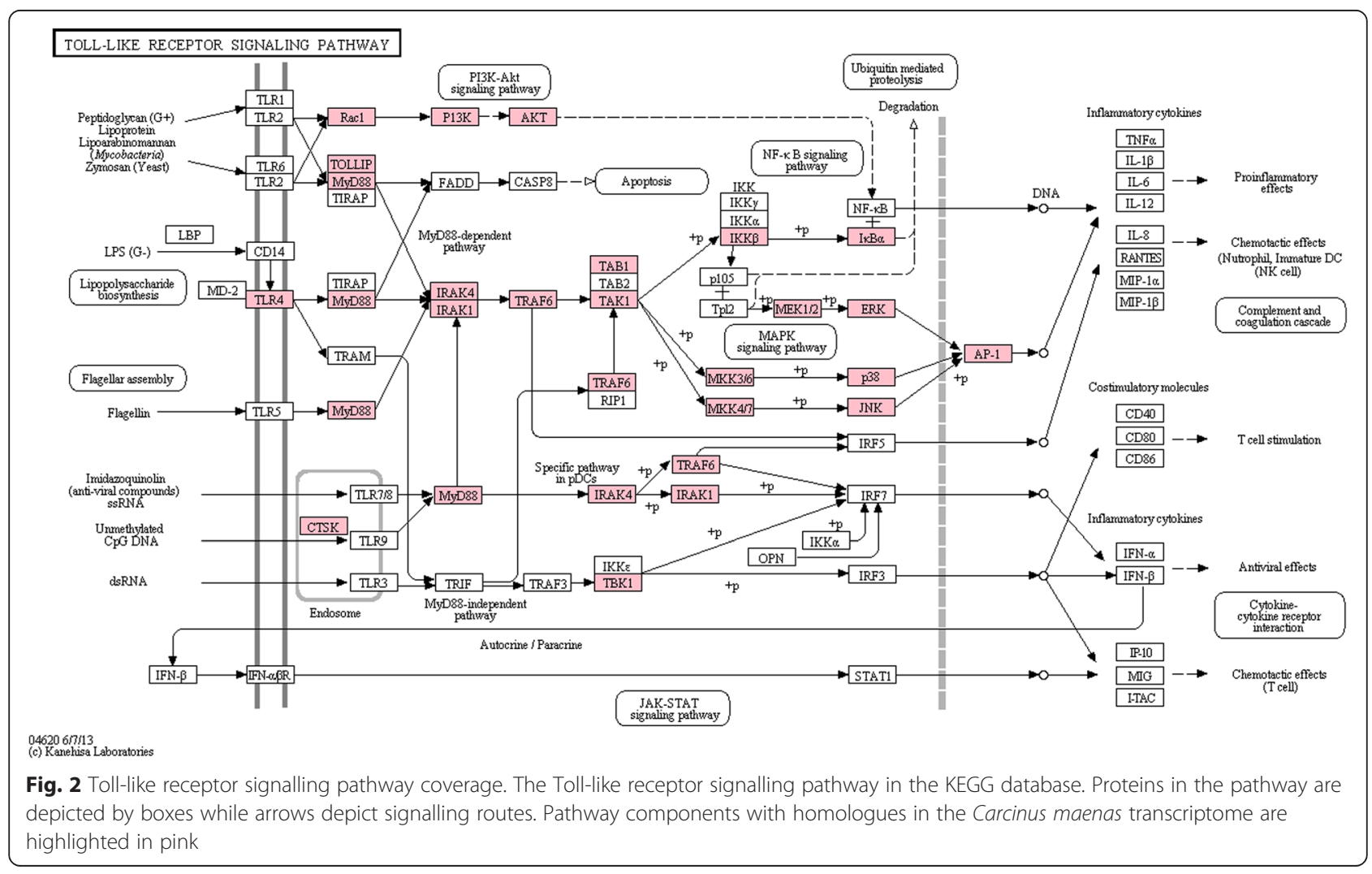


$\mathrm{N}$-terminal end to the nucleus where it regulates the expression of effector molecules [41]. Since the KEGG database does not contain the IMD pathway, the KEGG TNF-signalling pathway was used instead. As for the Toll-like receptor pathway, homologues also were found for most constituents of the TNF-signalling pathway (see Fig. 3). Manual identification of IMD pathway components derived from Kingsolver et al. [41] showed that FADD was the only absent component in the $C$. maenas transcriptome (Additional file 6). IMD itself was only expressed in three out of twelve tissues (eye, ovary and haemolymph) whereas the rest of the IMD pathway was expressed across all tissue types (Additional file 8).

\section{JAK-STAT signalling pathway}

The JAK-STAT signalling pathway mediates the response to chemical messenger molecules like cytokines. It has been shown that STAT signalling is activated upon WSSV infection in shrimp [43]. JAK tyrosine kinases bind to cytokine receptors and upon ligand binding they phosphorylate tyrosine residues on those receptors [44]. STAT is able to bind and subsequently be phosphorylated by JAK [44]. Following phosphorylation, STAT forms dimers, translocates to the nucleus and organizes the response to the signalling molecule by altering gene expression [44]. Inhibitors of JAK-STAT signalling are present at several stages and include dominant negative co-receptors, prevention of STAT recruitment by SOCS (suppressor of cytokine signalling) and protein inhibitors of activated STAT (PIAS) [44]. The KEGG reference pathway and coverage in the transcriptome are presented in Fig. 4. Most of the components of the JAK-STAT pathway have a homologue in the $C$. maenas transcriptome. The pathway in Fig. 4 shows that only the cytokine receptor was not identified by the KEGG annotation. However one transcript (comp79993_c0_seq2) showed highly significant sequence homology to the cytokine receptor of Harpegnathos saltator $(\mathrm{e}=3.00 \mathrm{e}-74)$ and the domeless receptor of Tribolium castaneum $(\mathrm{e}=2.00 \mathrm{e}-51)$.

\section{Response proteins}

The signalling cascade through the IMD, Toll and JAKSTAT pathways results in a transcriptional immune response mediated by transcription factors like STAT and NF-kB. One part of this immune response includes antimicrobial peptides (e.g. anti-lipopolysaccharide factor (ALF) and lysozyme), which have evolved to attack pathogens $[45,36]$. In addition to antimicrobial peptides, the

TNF SIGNALING PATHWAY
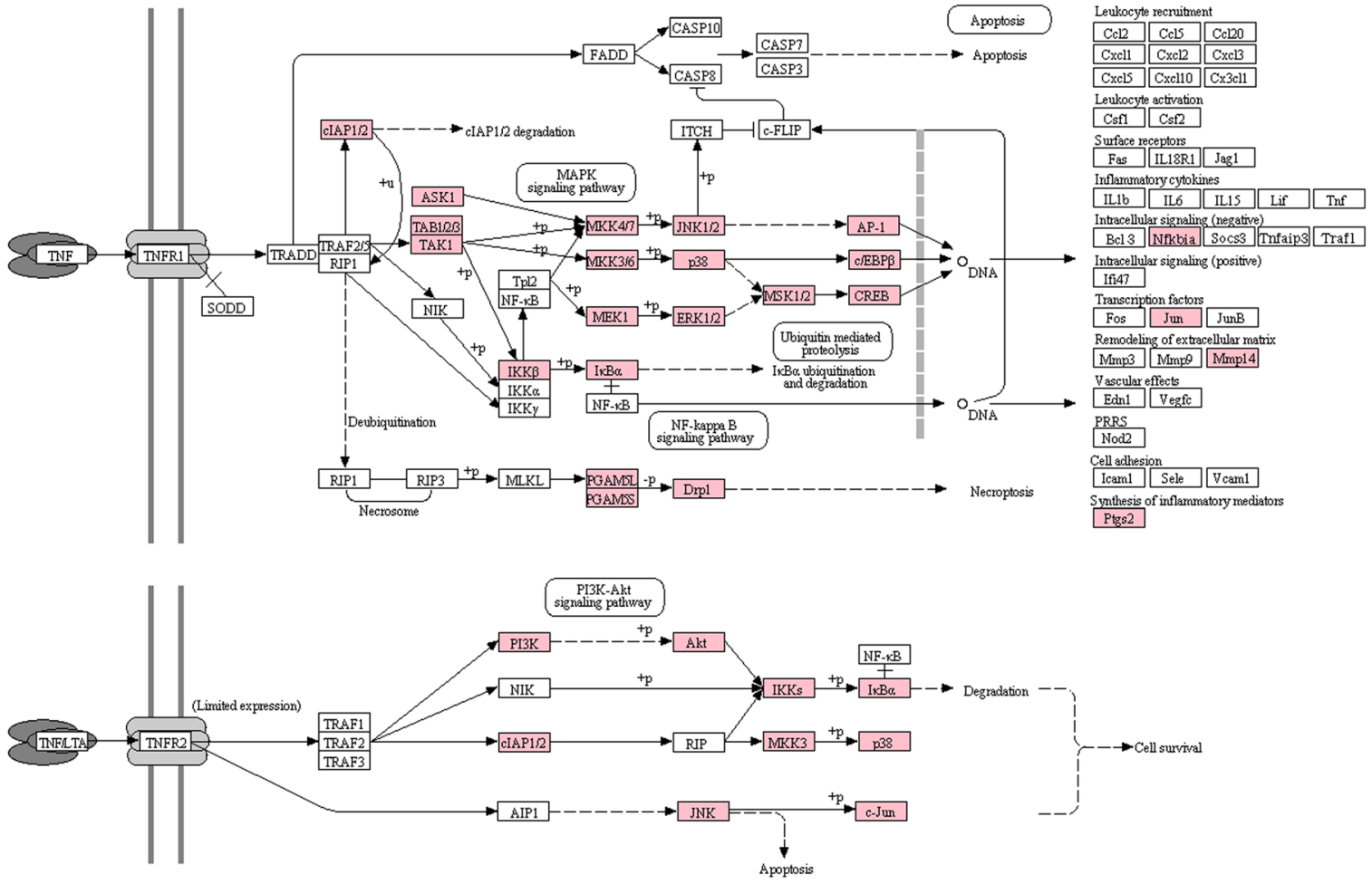

04668 5/27/13
(c) Kanehisa Laboratories

Fig. 3 TNF signalling pathway. Overview of the KEGG TNF signalling pathway, components depicted as in Fig. 2. Components with homologues in the Carcinus maenas transcriptome are highlighted in pink 


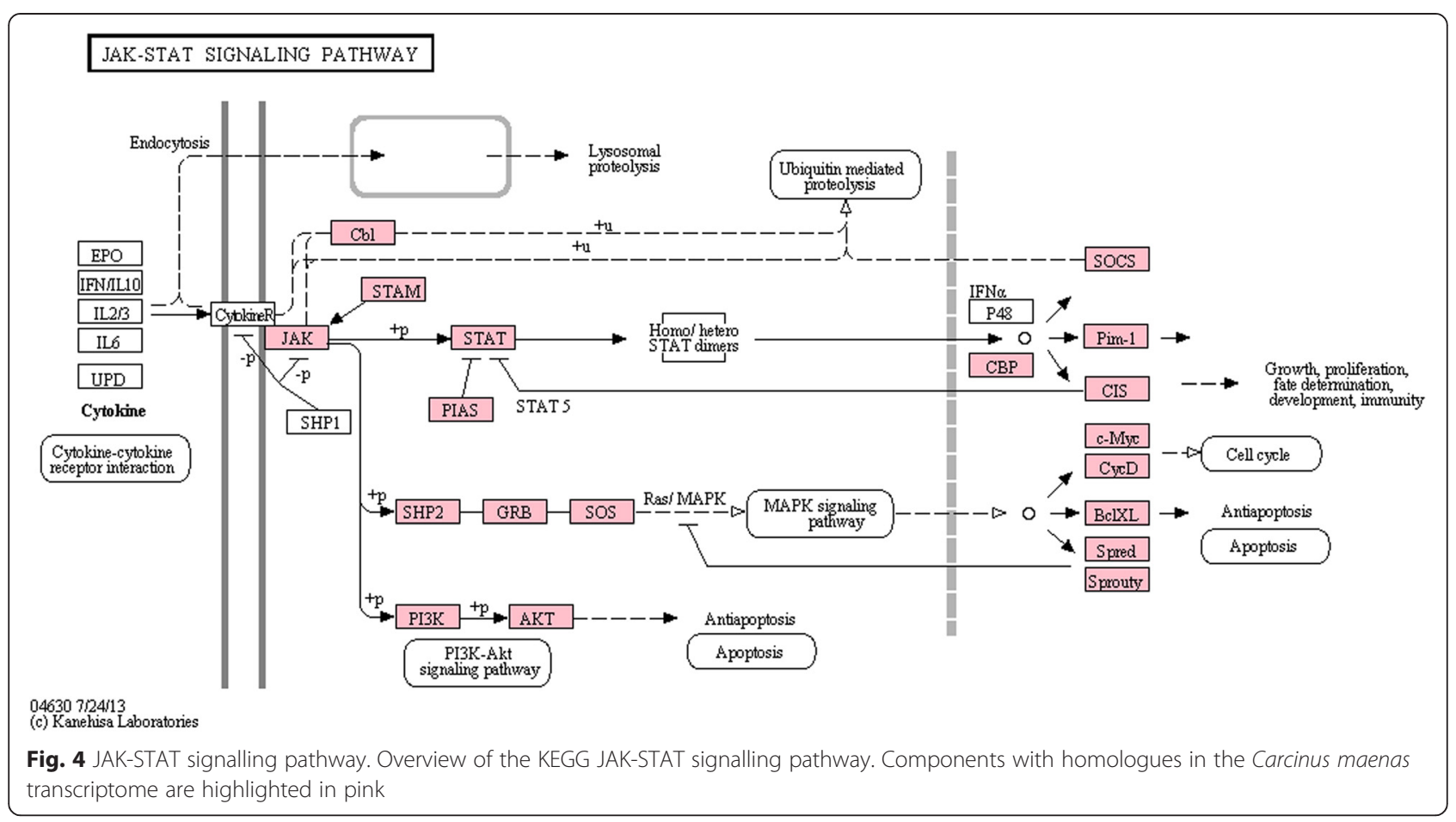

innate immune system also employs nitric oxide as a defensive molecule. Nitric oxide is an important redox activated signalling molecule and can be produced in large concentrations by nitric oxide synthase 2 (NOS-2), an enzyme synthesized as a response to PRR activation [46]. Response proteins identified in the C. maenas transcriptome are listed in Table 8 along with their target pathogen type, as described in Tassanakajon et al. [45]. Neither penaeidins [47] nor stylicins [48] were identified for $C$. maenas and we hypothesise that both are probably limited to penaeid shrimp species. The antimicrobial arsenal of C. maenas includes ALF, lysozyme, crustins, carcinin and inducible nitric oxide synthase. It is possible that the $C$. maenas transcriptome also contains novel anti-microbial peptides but to identify them will require exposure studies to trigger their activation.

\section{Melanization pathway}

The C. maenas innate immune system also contains a more direct response to pathogen infection in the form of the melanization pathway. Activated within minutes after infection, melanization damages and encapsulates invading

Table 8 Carcinus maenas Immune system response proteins

\begin{tabular}{|c|c|c|c|c|c|c|}
\hline Response protein & Transcript & Identity (\%) & Length & E-value & Query & Ancestor \\
\hline ALF & comp79835_c0_seq2 & 65.98 & 97 & $2.00 \mathrm{e}-34$ & $\begin{array}{l}\text { gi|302138013 : anti-lipopolysacharide factor } \\
\text { [Fenneropenaeus indicus] }\end{array}$ & Decapoda \\
\hline \multirow[t]{2}{*}{ Crustin } & comp88229_c1_seq1 & 56.36 & 110 & $8.00 \mathrm{e}-31$ & $\begin{array}{l}\text { gi|162945361 : crustin antimicrobial peptide [Scylla } \\
\text { paramamosain] }\end{array}$ & Portunoidea \\
\hline & comp91133_c0_seq1 & 65.38 & 78 & $7.00 \mathrm{e}-24$ & gi|255653868 : crustin 1 [Panulirus japonicus] & Pleocyemata \\
\hline Carcinin & comp88229_c1_seq1 & 86.36 & 110 & $1.00 \mathrm{e}-49$ & gi|18157188 : carcinin [Carcinus maenas] & $\begin{array}{l}\text { Carcinus } \\
\text { maenas }\end{array}$ \\
\hline \multirow[t]{3}{*}{ Lysozyme } & comp83352_c1_seq4 & 41.13 & 124 & $4.00 \mathrm{e}-23$ & $\begin{array}{l}\text { gi|675374133 : Lysozyme 1, partial [Stegodyphus } \\
\text { mimosarum] }\end{array}$ & Arthropoda \\
\hline & comp83352_c1_seq2 & 41.13 & 124 & $4.00 \mathrm{e}-23$ & $\begin{array}{l}\text { gi|675374133 : Lysozyme 1, partial [Stegodyphus } \\
\text { mimosarum] }\end{array}$ & Arthropoda \\
\hline & comp83352_c1_seq1 & 41.13 & 124 & $4.00 \mathrm{e}-23$ & $\begin{array}{l}\text { gi|675374133 : Lysozyme 1, partial [Stegodyphus } \\
\text { mimosarum] }\end{array}$ & Arthropoda \\
\hline iNOS & $\begin{array}{l}\text { comp89503_c2_seq } \\
(1-26)\end{array}$ & 52.6 & 308 & $1.00 \mathrm{e}-96$ & gi|13359094 : nitric oxide synthase 2 [Meriones unguiculatus] & Pancrustacea \\
\hline
\end{tabular}


pathogens with melanin [49]. The production of melanin from phenols and quinones generates reactive oxygen species that are damaging to the pathogen. Synthesis of quinones is catalyzed by the phenol oxidase (PO) enzyme. $\mathrm{PO}$ is readily available as a precursor (proPO) that is activated through proteolysis, ensuring a fast response time. Recognition of PAMPs by PRRs leads to activation of a serine protease cascade that ends with the activation of PO $[45,49,50]$. The proteolytic cascade is regulated by serpins that act as serine protease inhibitors [49]. Members of the melanization pathway as described in Tang 2009 [49] and transcripts with significant sequence similarity are listed in Additional file 6. The upstream proteases of proPO: MP1, Sp7 and the activating enzyme PPAE and prophenoloxidase itself are identified. Transcripts coding for the transcription factors serpent and lozenge, controlling the expression of proPO [49], and Peroxinectin, a protein that is associated with the proPO pathway and aids in cellular adhesion of haemocytes to pathogens [51] were also found. The expression of proPO varied across tissues (see Fig. 5), and was particularly high in the hepatopancreas and ovary.

\section{RNAi pathway}

RNA interference (RNAi) is one of the major antiviral pathways within the invertebrate innate immune system
[52]. The pathway produces small interfering RNA molecules (siRNAs) from virus derived dsRNA [41]. In short, dsRNA is recognized by Dicer proteins that subsequently cleave it to 21 nucleotide (nt) siRNAs. siRNAs are loaded into the RISC complex, which utilizes argonaute (Ago) protein to cleave viral RNAs targeted by the siRNA, and thus silencing expression [41]. The RNAi pathway can also be employed to silence specific genes in cells and forms the basis of antiviral immunity strategies, a topic explored in La Fauce et al. 2012 [53]. Identification of components of the RNAi pathway was based on those listed in Wang et al. 2014 [52], results are shown in Table 9. D. melanogaster has distinct functions for dicer-1 and dicer-2, the first being involved in the miRNA pathway and the latter in siRNA [54, 41, 55]. Both dicer- 1 and dicer- 2 were identified in C. maenas suggesting that a similar division of tasks could exist in this organism.

\section{Endocytosis pathway}

The endocytosis pathway plays a crucial role in viral challenges. Whereas some viruses are able to enter the cytosol directly, the majority require uptake via endocytosis [35]. Viral particles can enter endosomes via various endocytotic mechanisms (e.g. clathrin-mediated endocytosis,

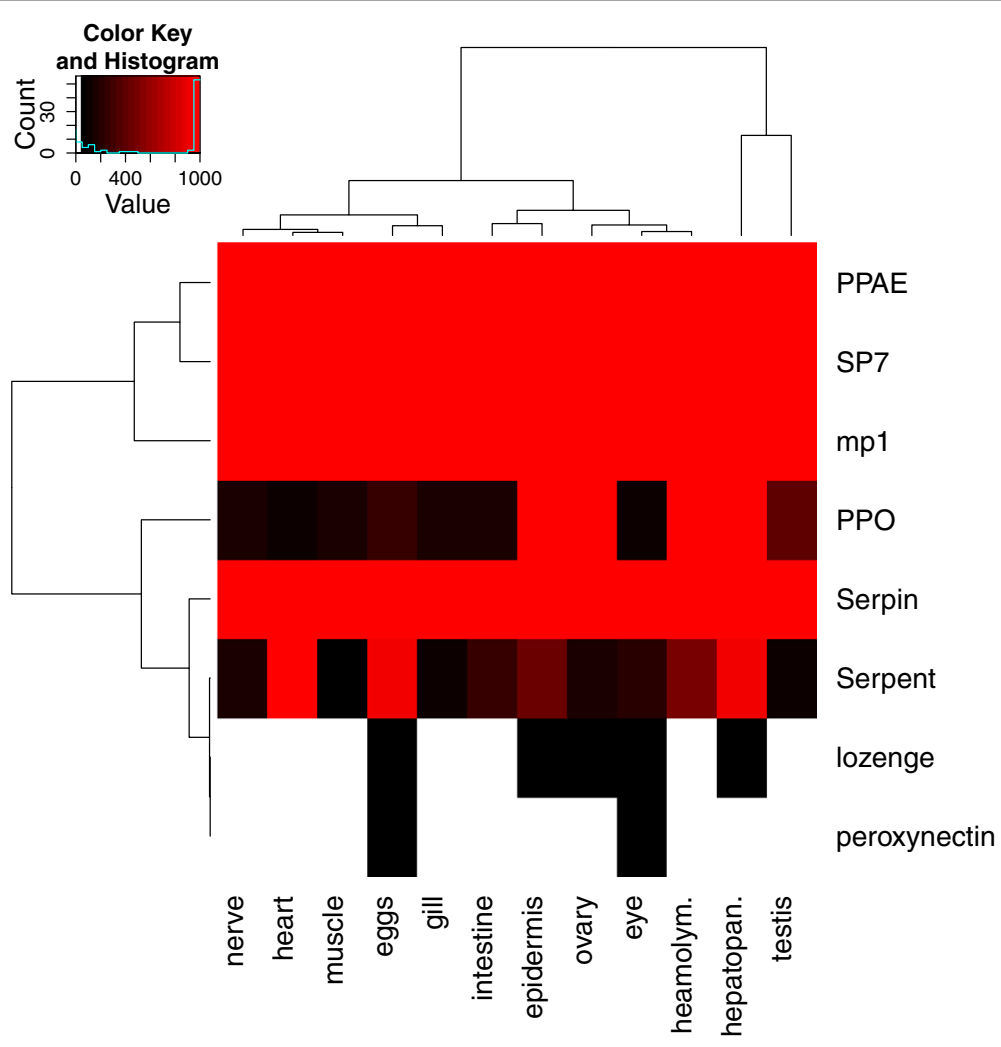

Fig. 5 Melanization pathway expression. Expression of melanization pathway components in twelve Carcinus maenas tissues. The expression values are presented in FPKM, values of 0 are coloured white and values over 10000 FPKM are binned together 
Table 9 Carcinus maenas RNAi pathway components

\begin{tabular}{|c|c|c|c|c|c|c|}
\hline RNAi & Transcript & Identity (\%) & Length & E-value & Query & Ancestor \\
\hline \multirow[t]{3}{*}{ TRBP } & comp79785_c0_seq (1-2) & 83.97 & 343 & $2.00 e-167$ & $\begin{array}{l}\text { gi|332271591 : TAR RNA-binding protein isoform } 1 \\
\text { [Marsupenaeus japonicus] }\end{array}$ & Decapoda \\
\hline & comp79200_c0_seq (1-2) & 36.74 & 460 & $4.00 \mathrm{e}-77$ & $\begin{array}{l}\text { gi|1 } 10825988 \text { : probable methyltransferase TARBP1 } \\
\text { [Homo sapiens] }\end{array}$ & Bilateria \\
\hline & comp49673_c0_seq1 & 46.34 & 205 & $2.00 \mathrm{e}-41$ & $\begin{array}{l}\text { gi| } 444174849 \text { : TAR RNA-binding protein } 1 \\
\text { [Penaeus monodon] }\end{array}$ & Decapoda \\
\hline \multirow[t]{2}{*}{ R2D2 } & comp79785_c0_seq (1-2) & 48.86 & 350 & $8.00 \mathrm{e}-81$ & gi|619831236 : R2D2 [Bemisia tabaci] & Pancrustacea \\
\hline & comp49673_c0_seq1 & 38.32 & 167 & $6.00 \mathrm{e}-24$ & gi|619831236 : R2D2 [Bemisia tabaci] & Pancrustacea \\
\hline drosha & comp87202_c0_seq1 & 93.37 & 829 & 0 & gi|396941645 : drosha [Marsupenaeus japonicus] & Decapoda \\
\hline Dicer2 & comp90354_c0_seq (1-11) & 47.73 & 1253 & 0 & gi|402534262 : Dicer-2 [Marsupenaeus japonicus] & Decapoda \\
\hline \multirow[t]{4}{*}{ Dicer1 } & comp85246_c1_seq1 & 77.95 & 1578 & 0 & gi|195424855 : dicer-1 [Litopenaeus vannamei] & Decapoda \\
\hline & comp90354_c0_seq (5-6) & 31 & 658 & $1.00 \mathrm{e}-83$ & gi|195424855 : dicer-1 [Litopenaeus vannamei] & Decapoda \\
\hline & comp55144_c0_seq1 & 61.06 & 113 & $3.00 \mathrm{e}-37$ & gi|283827860 : dicer-1 [Marsupenaeus japonicus] & Decapoda \\
\hline & comp77864_c(1-2)_seq (1-2) & 83.67 & 98 & $2.00 \mathrm{e}-40$ & gi|195424855 : dicer-1 [Litopenaeus vannamei] & Decapoda \\
\hline \multirow[t]{3}{*}{ ago2 } & comp81967_c(1-2)_seq1 & 37.16 & 802 & $5.00 e-139$ & gi|563729913 : argonaute2 [Penaeus monodon] & Decapoda \\
\hline & comp41784_c0_seq1 & 52.74 & 876 & 0 & gi|563729913 : argonaute2 [Penaeus monodon] & Decapoda \\
\hline & comp76466_c0_seq1 & 42.51 & 821 & 0 & gi|563729913 : argonaute2 [Penaeus monodon] & Decapoda \\
\hline \multirow[t]{3}{*}{ ago1 } & comp81967_c1_seq1 & 89.45 & 758 & 0 & $\begin{array}{l}\text { gi|321468117 : putative Argonaute protein } \\
\text { [Daphnia pulex] }\end{array}$ & Crustacea \\
\hline & comp41784_c0_seq1 & 43.65 & 811 & 0 & $\begin{array}{l}\text { gi|321468117 : putative Argonaute protein } \\
\text { [Daphnia pulex] }\end{array}$ & Crustacea \\
\hline & comp76466_c0_seq1 & 41.58 & 671 & $4.00 e-148$ & $\begin{array}{l}\text { gi|321468117: putative Argonaute protein } \\
\text { [Daphnia pulex] }\end{array}$ & Crustacea \\
\hline
\end{tabular}

caveolar-mediated endocytosis, or micropinocytosis). Decreasing $\mathrm{pH}$ in the endosome environment is a cue to the viral particles, which then penetrate into the cytosol [35]. This indicates that there are important interactions between components of the endocytosis pathway and viral proteins, e.g. cellular Rab7 can interact with the VP28 protein of the White Spot Syndrome Virus [56]. Therefore, information on the sequences and expression of the $C$. maenas endocytic system may aid in the study of viral infection. The mechanisms of endocytosis, maturation of endosomes and related signalling molecules are depicted in the KEGG pathway shown in Fig. 6. The number of identified components demonstrates that $C$. maenas contains an endocytic system that closely resembles this canonical KEGG pathway. The KEGG annotation did not yield transcripts similar to caveolin, an important constituent of caveolarmediated endocytosis. However a tBLASTn search of NCBI caveolin protein sequences in the transcriptome identified similarity between 'comp141181_c0_seq1' and caveolin-3-like isoform X2 (XP_006615923.1, Apis dorsata, $\mathrm{e}=1 \mathrm{e}-15)$. Expression of components of the endocytosis pathway is visualized in Fig. 7, and most of these components were expressed across all tissues. The muscle tissue showed an endocytosis expression profile that differs from the other tissues.

\section{Conclusions}

We produced an assembled transcriptome for C. maenas that consists of 153,699 loci and 212,427 transcripts and provides a significant molecular resource for wide studies into both basic and applied biology for this species. Comparisons run in the NCBI-nr database showed $30 \%$ of C. maenas transcripts had significant homology against known sequences, but a large number were novel transcripts that have yet to be characterized. Expression analysis revealed tissues and organ transcript specificity that mapped with gene ontology annotations relating to specific tissue/organ-related functions. Of particular relevance for studies into pathogenesis and disease, we identified the presence of a series of known targets and functional pathways including the RNAi pathway, Toll-like receptor signalling, IMD and JAK-STAT pathways that form part of their innate immune system.

\section{Methods}

\section{mRNA preparation}

Four individual Carcinus maenas were collected from Newton's Cove, Weymouth, UK and placed on ice prior to dissecting tissues and organs of interest (including gill, hepatopancreas, epidermis, eyes, intestine, haemolymph, muscle, heart, nerve, ovary, testis and eggs). All tissues and organs were immediately snap-frozen in 


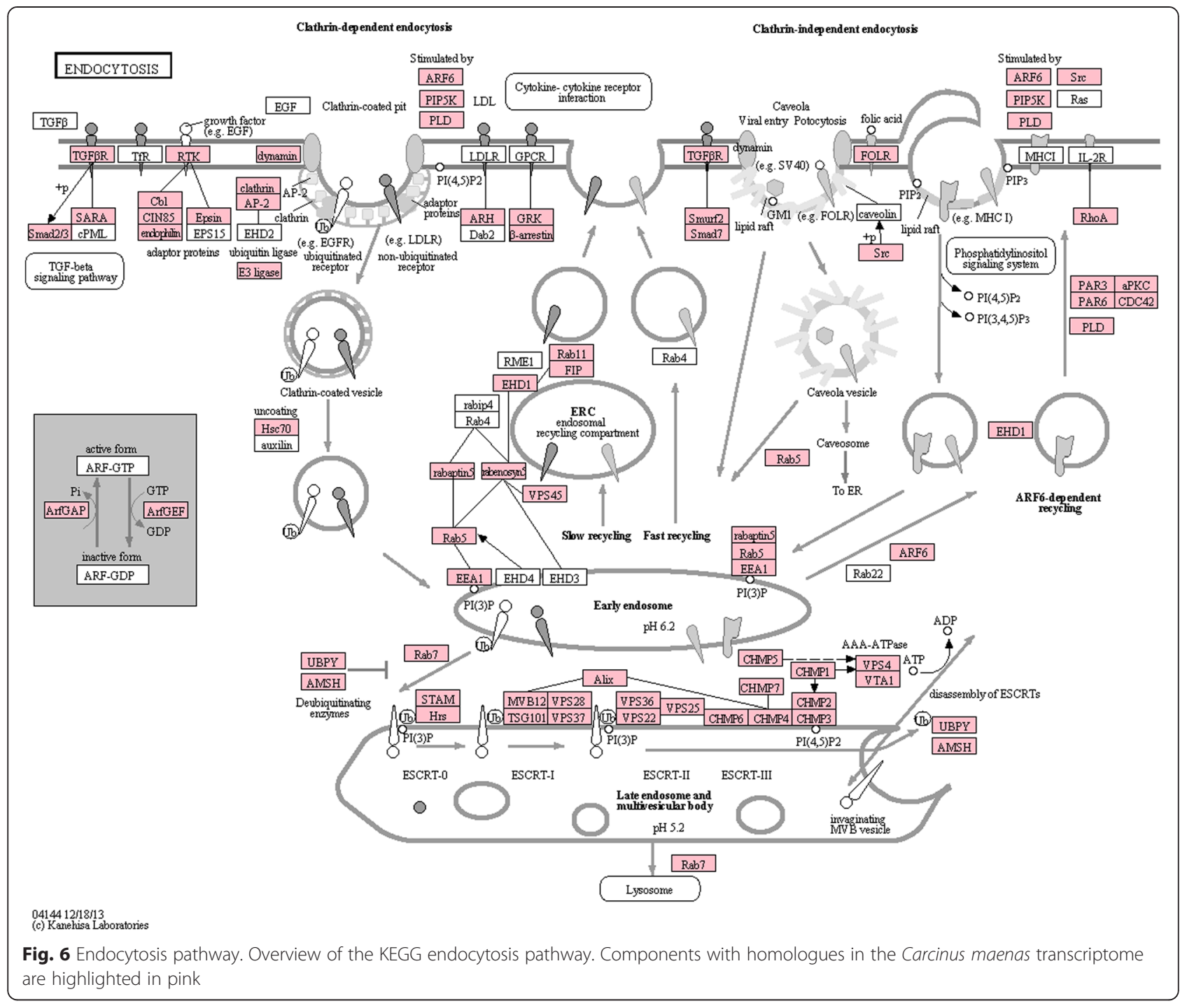

liquid nitrogen and transported to the University of Exeter for sample preparation and analysis.

RNA was extracted using Qiagen's miRNeasy mini kit, with on column DNase digestion, according to the manufacturer's instructions. RNA quality was measured using an Agilent 2100 Bioanalyzer with RNA 6000 nano kit (Agilent Technologies, CA, USA). cDNA libraries for each tissue were constructed using $2.5 \mu \mathrm{g}$ of RNA pooled from the four sampled individuals. ERCC Spike-In control mixes (Ambion via Life Technologies, Paisley, UK) were added to control for technical variation during sample preparation and sequencing, and analysed using manufacturer's guidelines. mRNA purification was performed via poly (A) enrichment using Tru-Seq Low Throughput protocol and reagents (Illumina, CA, USA). Finally, cDNA libraries were constructed using Epicentre's ScriptSeq v2 RNA-seq library preparation kit (Illumina). Each tissue was labelled with a unique barcode sequence to enable multiplexing of all samples across one lane whilst ensuring sequencing data from each tissue could be separated for analysis. Sequencing was performed on an Illumina HiSeq 2500 with the $2 \times 100$ bp paired-end read module.

\section{Transcriptome assembly}

Prior to transcriptome assembly, the sequence reads were processed to remove those with low confidence (as assigned by the sequencer). The first $12 \mathrm{bp}$ were trimmed from the reads to remove bias caused by random hexamer priming [57] and Illumina adapters were removed using Trimmomatic [58]. Trimmomatic was also used for quality trimming of the 3 ' end of the reads using a sliding window ( 4 bp with a minimal Phred quality of 30). Reads shorter that $70 \mathrm{bp}$ were discarded. Only read pairs where both reads passed the desired quality threshold were retained. Read pairs of all tissue libraries were pooled and used for de novo transcriptome assembly using the Trinity 


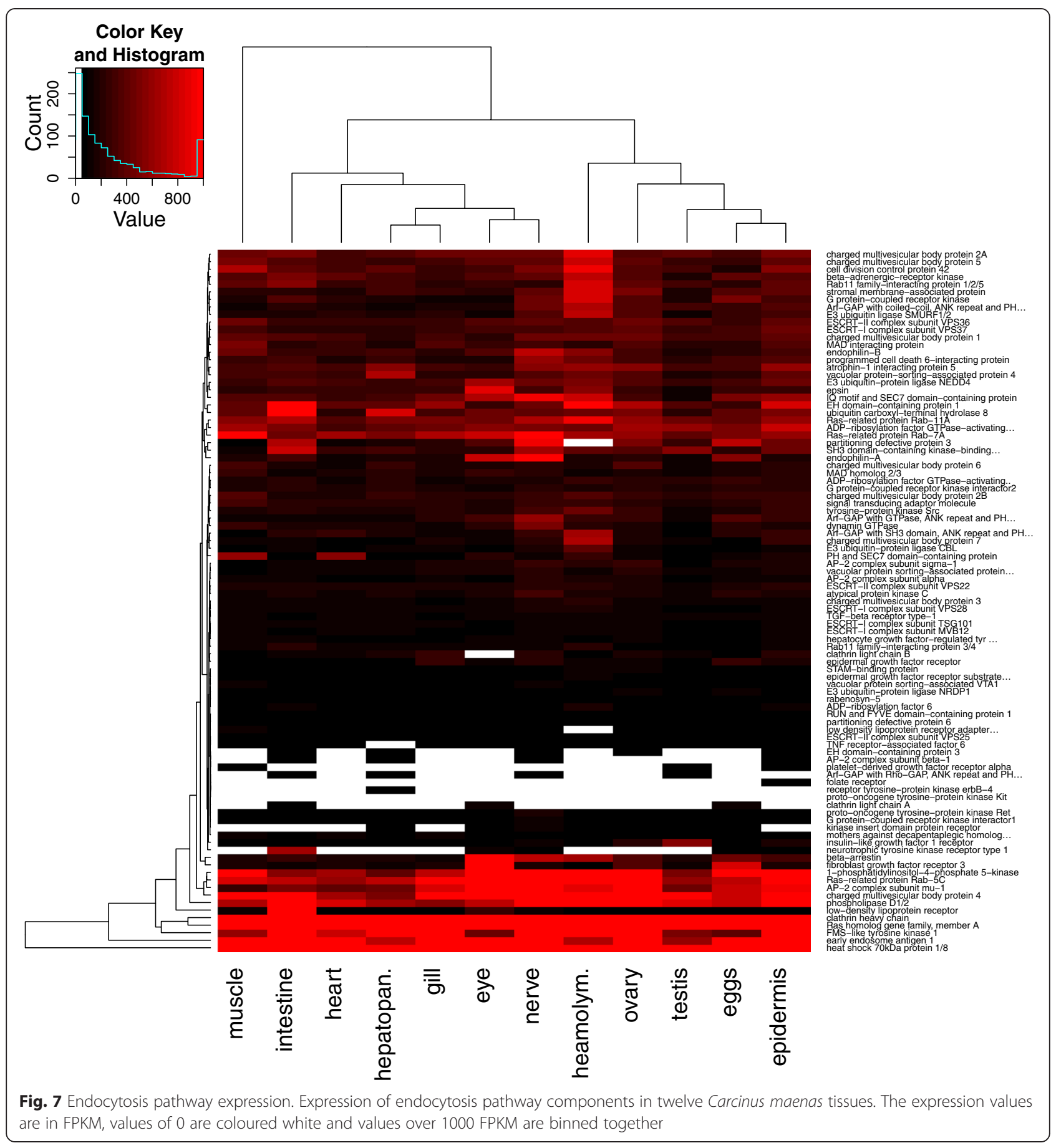

(2013-02-25 release) software package [9]. Transcripts with a length of 200 nucleotides or less were removed from the assembly. General transcriptome statistics, including maximal transcript length, mean transcript length and $\mathrm{N} 50$, of the resulting transcriptome were calculated with a custom $\mathrm{R}$ script. This Transcriptome Shotgun Assembly project has been deposited at DDBJ/ EMBL/GenBank under the accession GBXE00000000.
The version described in this paper is the first version, GBXE01000000.

\section{Transcriptome characterization}

The Trinotate suite (2013-08-26 release) [59] was used to annotate transcripts. Peptide coding regions were found through transdecoder and BLASTp $\mathrm{v}$ 2.2.28 (release 2013-07, e-value cutoff of 1e-5) was used to find 
sequence homology to UniProt/SwissProt. HMMR 3.1.b1 [60] and the Pfam database (version 27.0) were used to identify conserved protein domains. Additionally transmembrane regions were predicted with TMHMM-2.0c [61] and potential signal peptides identified with SignalP 4.1 [62]. Furthermore, homology searches were performed using BLASTx v 2.2.28 against the NCBI non-redundant (nr) protein database with an e-value cutoff of $1 \mathrm{e}-3$ and BLASTn against all available C. maenas ESTs in the NCBI database (2013-05-10; 15,558 ESTs in total), with an evalue cutoff of $1 \mathrm{e}-3$ and retaining the best 20 hits. The presence of highly conserved core eukaryotic genes was assessed using CEGMA 2.5 [29, 63]. Functional annotation analysis was conducted by assigning Molecular Function, Biological Process and Cellular Component Gene Ontology annotations to transcripts with BLAST2GO (v2.7.0) [30]. Finally, taxonomic classifications of the transcripts were determined and visualized using MEGAN 4 [64], and transcripts that did not map to the metazoan taxon were removed from the transcriptome assembly.

\section{Differential gene expression analysis}

For each tissue, reads were mapped to the Carcinus transcriptome (including non-metazoan transcripts) using bowtie2 [65] and RSEM [32] to obtain overall transcript expression values. Differential transcript expression was performed by comparing each tissue to the other eleven tissues, treating the latter as biological replicates. The calculations were performed with RSEM based on the edgeR package [66] with a dispersion parameter of 0.4 which is recommended for analysis without replicates. Transcripts with an FDR $<0.01$ were treated as differentially expressed. The lists of differentially expressed genes for each tissue were analysed for enrichment of Gene Ontology categories using BLAST2GO, and terms were deemed significant when $\mathrm{FDR}<0.05$.

\section{Pathway analysis}

KEGG ontology groups were assigned to assembled transcripts through the KEGG Automatic Annotation Server (KAAS) web service [33]. Next, the presence of components of reference pathways related to immune responses, including the toll-like receptor signalling pathway (map04620), TNF signalling pathway (map04668), JAK-STAT signalling pathway (map04630) and the endocytosis pathway (map04144) were visualized through the KAAS web service [33].

Since KEGG is focused on vertebrate pathways an additional, more flexible, pathway annotation strategy was required. For identification of a pathway component (e.g. Spätzle in the invertebrate Toll signalling pathway) the following steps were followed: 1 . Protein sequences for the component were downloaded from the NCBI protein database based on a search query. 2 . These sequences were used as input in a tBLASTn search against the assembled transcriptome (cut-off 1e-20). 3. For every transcript with BLAST hits, a filter was applied to select the best three query sequences based on first taxonomic distance to a reference taxon (tax_id $=6759$, Carcinus maenas) and secondly the e-value. 4 . When necessary, manual filtering to remove irrelevant sequences that were returned from NCBI. An R-script that performs this analysis is supplied in Additional file 9.

Expression of pathway components was derived by adding the RSEM-derived FPKM values for transcripts that were annotated to the component (either through KEGG annotation or the annotation stratagem explained above).

\section{Availability of supporting data}

The data set supporting the results of this article is available in the genbank Transcriptome Shotgun Assembly Sequence Database repository (http://www.ncbi.nlm.nih. gov/genbank/tsa) under the accession GBXE00000000. The version described in this paper is the first version, GBXE01000000.

\section{Additional files}

\begin{abstract}
Additional file 1: Cmaenas_transcript_lengths.pdf. This file contains a histogram of transcript lengths to illustrate the presence of fragments and full length transcripts in the transcriptome.

Additional file 2: Cmaenas_trinotate_annotation_report.txt. Output of the Trinotate annotation pipeline, tabular format. This file contains annotation information derived from the Trinotate annotation pipeline as decribed in the Methods section.
\end{abstract}

Additional file 3: Cmaenas_NCBIblastx.txt. Blastx results of transcripts to NCBI nr database, tabular format. This file contains information on sequence similarity between transcripts in the transcriptome and sequences in the NCBI non-redundant database.

Additional file 4: Cmaenas_transcriptome_GO_annot.txt. Transcript Gene Ontology annotation, tabular format. This file contains Gene Ontology annotations for transcripts.

Additional file 5: Tissue_GO_Enrichment.xlsx. Enriched Gene Ontology terms for analyzed tissues. This file shows which Gene Ontology terms are enriched for tissue specific differentially expressed genes.

Additional file 6: Pathway_components.xlsx. This file contains sequence similarities between components of immune pathways and the transcriptome. Additional file 7: toll_pathway_heatmap.pdf. Heatmap of expression values for components of the Toll-like signalling pathway.

Additional file 8: imd_pathway_heatmap.pdf. Heatmap of expression values for components of the IMD signalling pathway.

Additional file 9: Pathway_annotation.R. R script used to identify transcripts with significant sequence similarity to genes/proteins of interest.

\section{Abbreviations}

WSSV: White spot syndrome virus; GO: Gene ontology; FDR: False discovery rate; IMD: Immune deficiency; MAPK: Mitogen activated protein kinase; PRR: Pattern recognition receptors; PAMP: Pathogen associated molecular patterns; GNBP: Gram-negative binding proteins; PGRP: Peptidoglycan recognition proteins; TLR: Toll like receptor; FPKM: Fragments per kilo bases of exons per million mapped reads; ALF: Anti-lipopolysaccharide factor; PO: Phenol oxidase; RNAi: RNA interference. 


\section{Competing interests}

The authors declare that they have no competing interests.

\section{Authors' contributions}

BVE conducted the bioinformatics analysis and wrote the first version of the manuscript. LKB conducted the sample collection from wild crabs (together with KSB), RNA extraction and library construction for the sequencing experiments. EMS, CRT, GDS and RvA designed the study and supervised the laboratory experiments and data analysis. All authors contributed towards the design of the study and the final version of the manuscript.

\section{Acknowledgements}

The authors thank Audrey Farbos, Karen Moore and Konrad Paszkiewicz for facilitating the sequencing experiments. This work was funded by the Cefas Seedcorn Contract \#DP318 (to GDS) and the University of Exeter's Open Innovation Platform (to CRT, EMS and RvA). The Exeter Sequencing Facility was funded by a Wellcome Trust Institutional Strategic Support Award (WT097835MF).

\section{Author details}

${ }^{1}$ Biosciences, College of Life \& Environmental Sciences, University of Exeter, Geoffrey Pope Building, Exeter EX4 4QD, UK. European Union Reference Laboratory for Crustacean Diseases, Centre for Environment, Fisheries and Aquaculture Science (Cefas), Weymouth Laboratory, Weymouth, Dorset DT4 8UB, UK. ${ }^{3}$ Aquatic Health and Hygiene Division, Centre for Environment, Fisheries and Aquaculture Science (Cefas), Weymouth Laboratory, Weymouth, Dorset DT4 8UB, UK.

\section{Received: 2 December 2014 Accepted: 29 May 2015} Published online: 16 June 2015

\section{References}

1. Ge X, Chen H, Wang H, Shi A, Liu K. De novo assembly and annotation of Salvia splendens transcriptome using the illumina platform. PLoS One. 2014;9(3):e87693.

2. Uren Webster TM, Bury N, van Aerle R, Santos EM. Global transcriptome profiling reveals molecular mechanisms of metal tolerance in a chronically exposed wild population of brown trout. Environ Sci Technol. 2013;47(15):8869-77.

3. Gallardo-Escárate C, Valenzuela-Muñoz V, Nuñez-Acuña G. RNA-Seq analysis using de novo transcriptome assembly as a reference for the salmon louse caligus rogercresseyi. PLoS One. 2014;9(4):e92239. doi:10.1371/ journal.pone.0092239.

4. Yang W-J, Yuan G-R, Cong L, Xie Y-F, Wang J-J. De novo cloning and annotation of genes associated with immunity, detoxification and energy metabolism from the fat body of the oriental fruit fly, Bactrocera dorsalis. Plos One. 2014;9(4):e94470.

5. Zimmer CT, Maiwald F, Schorn C, Bass C, Ott MC, Nauen R. A de novo transcriptome of European pollen beetle populations and its analysis, with special reference to insecticide action and resistance. Insect Mol Biol. 2014;23:511-26.

6. Shentu X-P, Liu W-P, Zhan X-H, Xu Y-P, Xu J-F, Yu X-P, et al. Transcriptome sequencing and gene expression analysis of Trichoderma brevicompactum under different culture conditions. PLoS One. 2014;9(4):e94203.

7. Xie Y, Wu G, Tang J, Luo R, Patterson J, Liu S, et al. SOAPdenovo-trans: de novo transcriptome assembly with short RNA-Seq reads. Bioinformatics. 2014;30(12):1660-6.

8. Schulz MH, Zerbino DR, Vingron M, Birney E. Oases: robust de novo RNA-seq assembly across the dynamic range of expression levels. Bioinformatics. 2012;28(8):1086-92.

9. Grabherr MG, Haas BJ, Yassour M, Levin JZ, Thompson DA, Amit I, et al. Fulllength transcriptome assembly from RNA-Seq data without a reference genome. Nat Biotechnol. 2011;29(7):644-52.

10. EMBL-EBI. Ensembl Metazoa. EMB-EBI. 2014. http://metazoa.ensembl.org/ info/website/species.html. 2014

11. Global invasive species database. http://www.issg.org/database/welcome/. Accessed 2013

12. Darling JA, Bagley MJ, Roman J, Tepolt CK, Geller JB. Genetic patterns across multiple introductions of the globally invasive crab genus Carcinus. Mol Ecol. 2008;17(23):4992-5007.
13. Perry H. Carcinus maenas. USGS nonindigenous aquatic species database. 2014.

14. Hänfling B, Edwards F, Gherardi F. Invasive alien Crustacea: dispersal, establishment, impact and control. BioControl. 2011;56(4):573-95.

15. Jebali J, Chicano-Galvez E, Fernandez-Cisnal R, Banni M, Chouba L, Boussetta $\mathrm{H}$, et al. Proteomic analysis in caged Mediterranean crab (Carcinus maenas) and chemical contaminant exposure in Teboulba Harbour, Tunisia. Ecotoxicol Environ Saf. 2014;100:15-26.

16. Klassen L. A biological synopsis of the European green crab, Carcinus maenas. Can Manuscr Rep Fish Aquat Sci. 2007;2818:vii. +75pp.

17. Ben-Khedher S, Jebali J, Houas Z, Naweli H, Jrad A, Banni M, et al. Metals bioaccumulation and histopathological biomarkers in Carcinus maenas crab from Bizerta lagoon, Tunisia. Environ Sci Pollut Res Int. 2014 Mar;21(6):4343-57

18. Elumalai M, Antunes C, Guilhermino L. Enzymatic biomarkers in the crab Carcinus maenas from the Minho River estuary (NW Portugal) exposed to zinc and mercury. Chemosphere. 2007;66(7):1249-55.

19. Ghedira J, Jebali J, Banni M, Chouba L, Boussetta H, López-Barea J, et al. Use of oxidative stress biomarkers in Carcinus maenas to assess littoral zone contamination in Tunisia. Aquat Biol. 2011;14(1):87-98.

20. Chen CY, Dionne M, Mayes BM, Ward DM, Sturup S, Jackson BP. Mercury bioavailability and bioaccumulation in estuarine food webs in the Gulf of Maine. Environ Sci Technol. 2009;43(6):1804-10.

21. Rainbow PS, Black WH. Cadmium, zinc and the uptake of calcium by two crabs, Carcinus maenas and Eriocheir sinensis. Aquat Toxicol. 2005;72(1-2):45-65.

22. Pedersen KL, Bach LT, Bjerregaard P. Amount and metal composition of midgut gland metallothionein in shore crabs (Carcinus maenas) after exposure to cadmium in the food. Aquat Toxicol. 2014;150:182-8.

23. Windeatt KM, Handy RD. Effect of nanomaterials on the compound action potential of the shore crab, Carcinus maenas. Nanotoxicology. 2013;7(4):378-88.

24. Watts AJ, Lewis C, Goodhead RM, Beckett SJ, Moger J, Tyler CR, et al. Uptake and retention of microplastics by the shore crab Carcinus maenas. Environ Sci Technol. 2014;48(15):8823-30

25. Stentiford GD, Bonami JR, Alday-Sanz V. A critical review of susceptibility of crustaceans to taura syndrome, yellowhead disease and white spot disease and implications of inclusion of these diseases in European legislation. Aquaculture. 2009;291(1-2):1-17.

26. Stentiford GD, Neil DM, Peeler EJ, Shields JD, Small HJ, Flegel TW, et al. Disease will limit future food supply from the global crustacean fishery and aquaculture sectors. J Invertebr Pathol. 2012;110(2):141-57.

27. Bateman KS, Tew I, French C, Hicks RJ, Martin P, Munro J, et al. Susceptibility to infection and pathogenicity of White Spot Disease (WSD) in non-model crustacean host taxa from temperate regions. J Invertebr Pathol. 2012;110(3):340-51.

28. NCBI taxonomy Carcinus maenas. NCBI. 2014. http://www.ncbi.nlm.nih.gov/ Taxonomy/Browser/wwwtax.cgi?id=6759.

29. Parra G, Bradnam K, Korf I. CEGMA: a pipeline to accurately annotate core genes in eukaryotic genomes. Bioinformatics. 2007;23(9):1061-7.

30. Conesa A, Gotz S, Garcia-Gomez JM, Terol J, Talon M, Robles M. Blast2GO: a universal tool for annotation, visualization and analysis in functional genomics research. Bioinformatics. 2005;21(18):3674-6.

31. Salter SJ, Cox MJ, Turek EM, Calus ST, Cookson WO, Moffatt MF, et al. Reagent and laboratory contamination can critically impact sequence-based microbiome analyses. BMC Biol. 2014;12:87.

32. Li B, Dewey CN. RSEM: accurate transcript quantification from RNA-Seq data with or without a reference genome. BMC Bioinf. 2011;12:323.

33. Moriya Y, Itoh M, Okuda S, Yoshizawa AC, Kanehisa M. KAAS: an automatic genome annotation and pathway reconstruction server. Nucleic Acids Res. 2007;35(Web Server issue):W182-5.

34. Li X, Cui Z, Liu Y, Song C, Shi G. Transcriptome analysis and discovery of genes involved in immune pathways from hepatopancreas of microbial challenged mitten crab Eriocheir sinensis. PLoS One. 2013;8(7):e68233.

35. Mercer J, Schelhaas M, Helenius A. Virus entry by endocytosis. Annu Rev Biochem. 2010;79:803-33.

36. Christophides GK, Vlachou D, Kafatos FC. Comparative and functional genomics of the innate immune system in the malaria vector Anopheles gambiae. Immunol Rev. 2004;198(1):127-48.

37. McTaggart SJ, Conlon C, Colbourne JK, Blaxter ML, Little TJ. The components of the Daphnia pulex immune system as revealed by complete genome sequencing. BMC Genomics. 2009;10:175.

38. Liu H, Wu C, Matsuda Y, Kawabata S, Lee BL, Soderhall K, et al. Peptidoglycan activation of the proPO-system without a peptidoglycan receptor protein (PGRP)? Dev Comp Immunol. 2011;35(1):51-61. 
39. Armitage SA, Peuss R, Kurtz J. Dscam and pancrustacean immune memory-a review of the evidence. Dev Comp Immunol. 2015 Feb;48(2):315-23.

40. Ng TH, Chiang YA, Yeh YC, Wang HC. Review of Dscam-mediated immunity in shrimp and other arthropods. Dev Comp Immunol. 2014;46(2):129-38.

41. Kingsolver MB, Huang Z, Hardy RW. Insect antiviral innate immunity: pathways, effectors, and connections. J Mol Biol. 2013;425(24):4921-36.

42. Kawai T, Akira S. The role of pattern-recognition receptors in innate immunity: update on toll-like receptors. Nat Immunol. 2010;11(5):373-84.

43. Chen WY, Ho KC, Leu JH, Liu KF, Wang HC, Kou GH, et al. WSSV infection activates STAT in shrimp. Dev Comp Immunol. 2008;32(10):1142-50.

44. Morin-Poulard I, Vincent A, Crozatier M. The JAK-STAT pathway in blood cell formation and immunity. JAKSTAT. 2013;2(3):e25700.

45. Tassanakajon A, Somboonwiwat K, Supungul P, Tang S. Discovery of immune molecules and their crucial functions in shrimp immunity. Fish Shellfish Immunol. 2013:34(4):954-67.

46. Coleman JW. Nitric oxide in immunity and inflammation. Int Immunopharmacol. 2001:1(8):1397-406.

47. Destoumieux D, Bulet P, Loew D, Van Dorsselaer A, Rodriguez J, Bachere E. Penaeidins, a new family of antimicrobial peptides isolated from the shrimp Penaeus vannamei (Decapoda). J Biol Chem. 1997;272(45):28398-406.

48. Rolland JL, Abdelouahab M, Dupont J, Lefevre F, Bachere E, Romestand B. Stylicins, a new family of antimicrobial peptides from the pacific blue shrimp Litopenaeus stylirostris. Mol Immunol. 2010;47(6):1269-77.

49. Tang H. Regulation and function of the melanization reaction in Drosophila. Fly. 2009;3(1):105-11

50. Tang H, Kambris Z, Lemaitre B, Hashimoto C. Two proteases defining a melanization cascade in the immune system of Drosophila. J Biol Chem. 2006:281(38):28097-104.

51. Liu CH, Cheng W, Chen JC. The peroxinectin of white shrimp Litopenaeus vannamei is synthesised in the semi-granular and granular cells, and its transcription is up-regulated with Vibrio alginolyticus infection. Fish Shellfish Immunol. 2005;18(5):431-44.

52. Wang $P H$, Huang $T$, Zhang $X B$, He JG. Antiviral defense in shrimp: from innate immunity to viral infection. Antiviral Res. 2014;108:129-41. doi:10.1016/j.antiviral.2014.05.013.

53. La Fauce K, Owens L. RNA interference with special reference to combating viruses of crustacea. Indian J Virol. 2012;23(2):226-43.

54. Lee YS, Nakahara K, Pham JW, Kim K, He Z, Sontheimer EJ, et al. Distinct roles for Drosophila dicer-1 and dicer-2 in the siRNA/miRNA silencing pathways. Cell. 2004;117(1):69-81.

55. Bernstein E, Caudy AA, Hammond SM, Hannon GJ. Role for a bidentate ribonuclease in the initiation step of RNA interference. Nature. 2001;409(6818):363-6.

56. Verma AK, Gupta S, Verma S, Mishra A, Nagpure NS, Singh SP, et al. Interaction between shrimp and white spot syndrome virus through PmRab7-VP28 complex: an insight using simulation and docking studies. J Mol Model. 2013;19(3):1285-94.

57. Hansen KD, Brenner SE, Dudoit S. Biases in Illumina transcriptome sequencing caused by random hexamer priming. Nucleic Acids Res. 2010;38(12):e131.

58. Lohse M, Bolger AM, Nagel A, Fernie AR, Lunn JE, Stitt M, et al. RobiNA: a user-friendly, integrated software solution for RNA-Seq-based transcriptomics. Nucleic Acids Res. 2012;40(Web Server issue):W622-7.

59. Trinotate. http://trinotate.github.io/

60. Finn RD, Clements J, Eddy SR. HMMER web server: interactive sequence similarity searching. Nucleic Acids Res. 2011;39(Web Server issue):W29-37.

61. Krogh A, Larsson B, von Heijne G, Sonnhammer ELL. Predicting transmembrane protein topology with a hidden markov model: application to complete genomes. J Mol Biol. 2001;305(3):567-80.

62. Petersen TN, Brunak S, von Heijne G, Nielsen H. SignalP 4.0: discriminating signal peptides from transmembrane regions. Nat Methods. 2011;8(10):785-6.

63. Parra G, Bradnam K, Ning Z, Keane T, Korf I. Assessing the gene space in draft genomes. Nucleic Acids Res. 2009;37(1):289-97.

64. Huson DH, Mitra S, Ruscheweyh HJ, Weber N, Schuster SC. Integrative analysis of environmental sequences using MEGAN4. Genome Res. 2011;21(9):1552-60.

65. Langmead B, Salzberg SL. Fast gapped-read alignment with Bowtie 2. Nat Methods. 2012;9(4):357-9.

66. Robinson MD, McCarthy DJ, Smyth GK. edgeR: a Bioconductor package for differential expression analysis of digital gene expression data. Bioinformatics. 2010;26(1):139-40.

\section{Submit your next manuscript to BioMed Central and take full advantage of:}

- Convenient online submission

- Thorough peer review

- No space constraints or color figure charges

- Immediate publication on acceptance

- Inclusion in PubMed, CAS, Scopus and Google Scholar

- Research which is freely available for redistribution

Submit your manuscript at www.biomedcentral.com/submit 